that is badly needed, but the results of which might be rendered unintelligible because of the invention of a host of new initials by the experimenters.

Each volume is written by about 20 or 30 contributors, all of whom are experts in their specialized field. They achieve a high level of accuracy and are ruthless in their determination not to omit anything that might be relevant. As a source of reference for specialists, this book could hardly be bettered, though it is likely each will be able to cope only with the volume or volumes that fall within his or her speciality. There is, however, one volume that is an exception, because it can be read for pleasure as well as enlightenment. It differs from the rest in that it is written in its entirety by two authors, O. J. Grüsser and T. Landis. Although their first language is German, their writing is less turgid and more perspicuous than that of most of the other contributors. Apart from covering the obvious topics suggested by the title ("Visual Agnosias and Related Disturbances of Visual Perception and Cognition"), such as field defects, hemianopia, and prosopagnosia, they give readable introductions to psychological and neurophysiological theories and findings on almost every aspect of vision, including colour and motion perception, visual illusions, electroencephalography and eye movements. For light relief, they present a history of research on vision starting with Empedocles and proceeding through Galen, Avicenna, Kepler and Newton to Munk and Exner. Their penchant for history is also revealed in illuminating accounts of such matters as Bronze Age drawings and the development of script, starting with cuneiform. Unlike many of the other authors, who seem to be gritting their teeth while they grind through their allotted task, they write with a genuine enthusiasm, which has not precluded scholarship. Indeed, they are duly cautious in their interpretation of the many visual disorders they survey.

The volumes are sumptuously produced with a large number of diagrams and other illustrations, many in colour. The indices, on the other hand, are a disgrace. Few proper names are included - David Marr is in, Dave Hubel is out. Moreover, one searches in vain for many topics covered in the book. This lapse is particularly regrettable in a series that is primarily intended as a work of reference. Despite or perhaps because of the massive amount of information it contains, few workers will wish to own the whole set. It may be a feast, but it is a rather indigestible one.

Stuart Sutherland is in the Laboratory of Experimental Psychology, University of Sussex, Brighton BN1 9QG, UK.

\section{Bonny baby}

\author{
J. R. Fozard
}

Glaxo: A History to 1962. By R. P. T. Davenport-Hines and Judy Slinn. Cam bridge University Press: 1992. Pp. 406. £55, \$110.

THERE can be few readers who would find this book in its entirety a riveting read. In their scholarly, deeply factual account of the early development of Glaxo, the world's second largest pharmaceutical company and the current role model for much of the industry, Daven-

\section{IMAGE UNAVAILABLE FOR COPYRIGHT REASONS}

trading company founded by Joseph Nathan, a Jew from London's East End; through baby foods based on dried milk ('Glaxo', a euphonious sound-alike for 'Lacto' that proved acceptable to the Trades Mark Office), the first faltering steps into pharmaceuticals (vitamin products and antibiotics) and overseas markets (initially the British Commonwealth; belatedly, the crucial markets of Europe, North America and Japan), and the important acquisitions (Allen and Hanburys, Evans Medical); to the status of a leading British company, which Glaxo had become by 1962 .

Those who, like me, would seek in such a book clues to the success of the present-day Glaxo will find ․ Chapter 8, "Research and development: a strategy of क् science", the most revealing. The early lessons $\frac{\mathrm{x}}{\mathrm{N}}$ learnt during the development and marketing of vitamin $B_{12}$, various antibiotics, corticosteroids, vaccines and sundry minor medicines were used to shape strategies that were implemented by men of true professional quality, such as Jephcott, Henry Tizard (board member) Growth business - Glaxo advertisement at King's Cross, London, In 1921. and Tom Macrae (research director). The essence of their pragmatism can be

port-Hines and Slinn provide not only the nuts and bolts of the story but the thread diameters to several decimal places. Unfortunately, because of the plethora of detail and despite some well-chosen illustrations, some sections make tedious reading: can one really appreciate the significance of "when in 1908 the Infant Welfare Centre at Rotherham began supplying Glaxo powder to mothers, 3,912 lbs was issued in the first sixteen months of the scheme" or the financial details of the fledgling Pakistan company in pounds and lakhs? On the other hand, detail can be fascinating, such as the personal characteristics of the principal players, in particular A. L. Bacharach, an early scientific recruit to Glaxo who proved a pervasive and positive influence throughout the organization. Or, for example, the consequences of company chairman Harry Jephcott's blunder in telling a visiting Merck executive that the anti-pernicious anaemia factor that both companies were attempting to isolate was pinkish red. As a scientist, I found that the tedious fractionally outweighed the fascinating; I could well imagine my business colleagues would say the reverse.

Be that as it may, this encyclopaedic effort has to be praised unreservedly for what it is: the definitive record of the origins of Glaxo from the antipodean gleaned from statements such as "Committees can never take action successfully and effectively. In the finality individuals have to do whatever is to be done" (Jephcott), "The ideal director of research .... is a strategist first and foremost. ... He must inspire his own staff with the joy of practical achievement. He must deal gently but firmly with accountants who do not like doing what has never been done before. ... It is not at all necessary that he should be a distinguished scientist, though he must be or must have been an experimenter" (Tizard) or "My God was that $10 \%$ stretched" (Macrae, referring to the board ruling that $10 \%$ of the research department's total income could be spent on whatever it liked).

It is not implausible that such attitudes were spliced firmly into the corporate Glaxo genome and that their expression over the years has been fundamental to Glaxo's success. However, the Glaxo Group of 1993 is very different in size, structure and organization from that of 1962; a second nuts-and-bolts story of a very different set of personalities and circumstances will be required for any such genetic traits to be discerned.

J. R. Fozard is in the Department of Preclinical Research, Sandoz Pharma Ltd, CH-4002 Basel, Switzerland. 